\title{
Genomics insights into different cellobiose hydrolysis activities in two Trichoderma hamatum strains
}

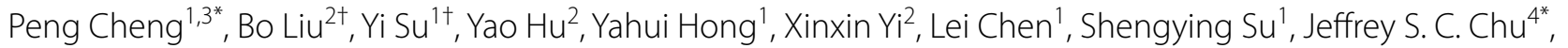
Nansheng Chen ${ }^{2,5^{*}}$ and Xingyao Xiong ${ }^{1}$

\begin{abstract}
Background: Efficient biomass bioconversion is a promising solution to alternative energy resources and environmental issues associated with lignocellulosic wastes. The Trichoderma species of cellulolytic fungi have strong cellulose-degrading capability, and their cellulase systems have been extensively studied. Currently, a major limitation of Trichoderma strains is their low production of $\beta$-glucosidases.

Results: We isolated two Trichoderma hamatum strains YYH13 and YYH16 with drastically different cellulose degrading efficiencies. YYH13 has higher cellobiose-hydrolyzing efficiency. To understand mechanisms underlying such differences, we sequenced the genomes of YYH13 and YYH16, which are essentially identical (38.93 and $38.92 \mathrm{Mb}$, respectively) and are similar to that of the T. hamatum strain GD12. Using GeneMark-ES, we annotated 11,316 and 11,755 protein-coding genes in YYH13 and YYH16, respectively. Comparative analysis identified 13 functionally important genes in YYH13 under positive selection. Through examining orthologous relationships, we identified 172,655, and 320 genome-specific genes in YYH13, YYH16, and GD12, respectively. We found 15 protease families that show differences between YYH13 and YYH16. Enzymatic tests showed that exoglucanase, endoglucanase, and $\beta$-glucosidase activities were higher in YYH13 than YYH16. Additionally, YYH13 contains 10 families of carbohydrateactive enzymes, including $\mathrm{GH} 1, \mathrm{GH} 3, \mathrm{GH} 18, \mathrm{GH} 35$, and GH55 families of chitinases, glucosidases, galactosidases, and glucanases, which are subject to stronger positive selection pressure. Furthermore, we found that the $\beta$-glucosidase gene (YYH1311079) and pGEX-KG/YYH1311079 bacterial expression vector may provide valuable insight for designing $\beta$-glucosidase with higher cellobiose-hydrolyzing efficiencies.
\end{abstract}

Conclusions: This study suggests that the YYH13 strain of T. hamatum has the potential to serve as a model organism for producing cellulase because of its strong ability to efficiently degrade cellulosic biomass. The genome sequences of YYH13 and YYH16 represents a valuable resource for studying efficient production of biofuels.

Keywords: Trichoderma hamatum, Comparative genomics, Genetic diversity, $\beta$-Glucosidase, Cellobiose

\footnotetext{
*Correspondence: cp232@163.com; jeffreychu@frasergen.com; chenn@

sfu.ca

${ }^{\dagger}$ Bo Liu and Yi Su contributed equally to this work

1 Hunan Provincial Key Laboratory of Phytohormones and Growth Development, Hunan Provincial Key Laboratory for Crop Germplasm Innovation and Utilization, Hunan Agricultural University, Changsha 410128, China

${ }^{2}$ College of Life Science and Technology, Huazhong Agricultural University, Wuhan 430070, China

${ }^{4}$ Wuhan Frasergen Bioinformatics Co. Ltd, 666 Gaoxin Road, East Lake High-tech Zone, Wuahn 430075, China

Full list of author information is available at the end of the article
} 


\section{Background}

The growing worldwide demand for energy and the desire to reduce dependency on fossil fuels have triggered increased interest in identifying alternative energy resources, especially liquid biofuels, such as bioethanol and biodiesel. Because renewable lignocellulosic biomass is generally considered to be cheaper resource, no competition with agricultural production and cleaner raw material for ethanol production comparing with oilbased fuels [1], efforts in generating liquid biofuels from renewable lignocellulosic biomass have been made.

Biodegradation of lignocellulosic residues is a process that is primarily performed by microorganisms that can enzymatically digest polymeric sugars to capture soluble monosaccharides and disaccharides as carbon sources for energy production. This ability is exploited by biotechnological industries to obtain large quantities of active, stable, and specific enzymes using agricultural waste solids as raw materials [2]. In 2015, the global market for industrial enzymes is expected to reach more than 4 billion dollars [3]. The industrial enzymes market prefers microbial enzymes because they are more stable than enzymes from plants and animals. Fungi are particularly preferred for enzyme production because they are secreted as enzyme complexes that function in a synergistic manner, and their production is a relatively easy and inexpensive [4].

Currently, most kinds of commercial cellulase (including $\beta$-glucosidase) are derived from fungi, e.g. Trichoderma, Aspergillus, Phanerochaete, Schizophyllum and Penicillium [5]. Aspergillus niger is used to produce many pectinases [6,7] and hemicellulases [8] in industry. Trichoderma reesei QM6a was found to be a good producer of cellulose [9]. Due to their efficiency in producing and secreting a broad range of cellulases and hemicellulases, both of these fungi have been the focus of extensive studies on glycoside hydrolase (GH) discovery, and there is a marked effort to understand the regulation of the expression of genes that encoding them.

Species in Trichoderma spp. is a widely distributed saprophytic ascomycete and is well known for their biocontrol ability and lignocellulose degradation abilities. Recent genome sequencing projects have targeted eight species [10]: T. reesei, Trichoderma virens, Trichoderma atroviride, Trichoderma harzianum, Trichoderma longibrachiatum, Trichoderma asperellum, Trichoderma hamatum, and Trichoderma citrinoviride. It was observed that the tropical species $T$. reesei enhances the induction of its entire cellulolytic and hemicellulolytic arsenal when facing temperate $R$. solani, which is a very unlikely prey/host for this species in nature, whereas such a response is not observed for $T$. atroviride or $T$. virens. The presence of a basidiomycete fungus may thus signal the availability of predigested plant biomass to $T$. reesei, consistent with the hypothesis that this species became a saprotroph by following basidiomycetes into their habitat [11].

A striking weakness of the Trichoderma system is that many Trichoderma strains isolated from the wild lack necessary lignocellulolytic enzymes for efficient bioconversion processes [12], especially $\beta$-glucosidases, which are considered key rate- limiting enzymes in the process of cellulose degradation [13]. For example, under cellulase-inducing conditions, the production of secreted $\beta$-glucosidase comprises only about $1 \%$ of the total T. reesei cellulase [14], indicating that the hydrolysis of cellobiose constitutes a rate-limiting step during the enzymatic processing of cellulose $[15,16]$. Although commercial cellulase is available, many of the most well-known biomass- degrading fungi display low $\beta$-glucosidase (cellobiose) activity, thus the initial bioconversion of biomass to sugars remains a key bottleneck in the process of biofuel production. Thus, searching for Trichoderma strains with strong $\beta$-glucosidase activities is primary importance.

$\beta$-Glucosidases (EC 3.2.1.21) are found in all domains of living organisms, where they play essential roles in the removal of nonreducing terminal glucosyl residues from saccharides and glycosides. $\beta$-Glucosidases function in glycolipid and exogenous glycoside metabolism in animals, defense, cell wall lignification, cell wall $\beta$-glucan turnover, phytohormone activation, and release of aromatic compounds in plants, and biomass conversion in microorganisms. We identified T. hamatum strains from cultivated soil in HeJiaqiao, LiLing, Hunan province, China, among which YYH13 exhibited much higher antimicrobial activity against the bacterial wilt pathogen because of its higher expression of specific $\beta$-glucanase and chitinases, which play important roles as hydrolytic enzymes during cell wall degradation [17].

In this study, we carried out genome-wide comparative analysis of $T$. hamatum and other model organisms with publicly available genomes including $T$. atroviride, $T$. harzianum, T. reesei, and T. viren, which will help us explain the possible reason for YYH13 and YYH16 genome difference. To examine whether YYH13 has higher cellobiose hydrolyzing efficiency, we subjected YYH13 and YYH16 to exoglucanase, endoglucanase, $\beta$-glucosidase activity tests and expression assay of GH1 genes. In total, our results will provide a valuable resource and the genome sequence of T. hamatum YYH13 represents a new strain that can be used for further studies on the genetic bases of efficiently degrade cellulosic biomass for biofuel production by the Trichoderma species. 


\section{Results and discussion}

YYH13 and YYH16 are two strains of T. hamatum with different cellulose degradation activity

Trichoderma hamatum have unique mycelium, spore, and colonial morphology [18]. By colonial morphology analysis (Fig. 1a), we found YYH13 and YYH16 strains had moderate colony growth with white and dense colonies. The mycelium was white and the spore heads were green. YYH13 and YYH16 strains isolated in this study showed typical T. hamatum phenotype. However, these two strains had different mycelial growth when they started at the same spore densities $\left(10^{6}\right.$ spores $\left./ \mathrm{mL}\right)$, with YYH13 and YYH16 spore density generate difference after 48 h (Fig. 1b).

Many alternative mechanisms can cause microorganism growth inhibition, including mycoparasitism, bacteriolysis, nutrient, and space competition [19]. Trichoderma produces many hydrolases that degrade the cell wall, including chitinases, cellulases, xylanase, glucanase and proteases. These enzymes are usually extracellular, of low molecular weight and highly stable. They may be produced in multiple forms or isozymes that differ in size, regulation, and ability. This trait has often been utilized as a means of in vitro screening for biocontrol candidates. Various cell wall degrading enzymes play a very important role in the process of hyperparasitism. Some Trichoderma species have strong cellulosedegrading properties because they can secrete an enzyme system capable of degrading crystalline cellulose [20]. For example, T. reesei QM6a strain possesses a remarkable set of genes encoding hydrolytic enzymes.

We performed cellulose degradation test using filter paper as the substrate. As shown in Fig. 1e, filter paper degradation efficiency of YYH13 at $96 \mathrm{~h}$ was $37.14 \%$ higher than that of $\mathrm{YYH} 16$ at the same time point $(P<0.05)$, YYH13 also showed much stronger capability for the degradation of cellulose (Fig. 1e). The filter paper degradation analysis indicated that the action of its enzymes is very potential in insoluble cellulosic substrates, due to the crystalline structure of filter paper, degradation of the filter paper would imply multiple cellulose activities, including exoglucanase activities because these enzymes work in crystalline regions. In conclusion, we observed that both YYH13 and YYH16 had rapid growth rates with the similar colonal morphologies, and similar growth curves. Despite of these similarities, these two T. hamatum strains show significant differences in cellulose degradation activities.

\section{Genome sequencing and assembly of YYH13 and YYH16}

To identify the genetic causes of the observed phenotypic differences, we sequenced the genomes of these two T. hamatum strains used Illumina Hiseq sequencing platform (Table 1). According to the sizes of assembled genomes of various Trichoderma species (Table 2), our sequencing data achieved approximately $292 \times$ and $95 \times$, respectively. A 17-mer genomic survey using approximately $70 \times$ of data showed that YYH13 had a sharp peak at approximately $60 \times$, indicating low levels of heterozygosity and low levels of repetitive content. Although YYH16 showed a similar low level of heterozygosity, its distribution had a longer tail at higher depths, suggesting more repetitive content (Fig. 2). The K-mer analysis estimated $15 \%$ more repetitive sequences than $\mathrm{YYH} 13$ (Table 3). We carried out de novo genome assembly to obtain draft genome assemblies using SOAPdenovo. We obtained 608 and 2550 scaffolds with N50 of 578.2 and $41.6 \mathrm{~Kb}$ in YYH13 and YYH16, respectively. The final genome assembly sizes for the two genomes were 38.93 and $38.92 \mathrm{Mb}$ (Table 2), respectively, which fell within the known range for the genomes of Trichoderma species [21-24].

To confirm that YYH13 and YYH16 are species of T. hamatum, we identified the rDNA gene cluster and extracted the sequences for ITS1 and ITS2. Constructing a phylogenetic tree using these ITS sequences with
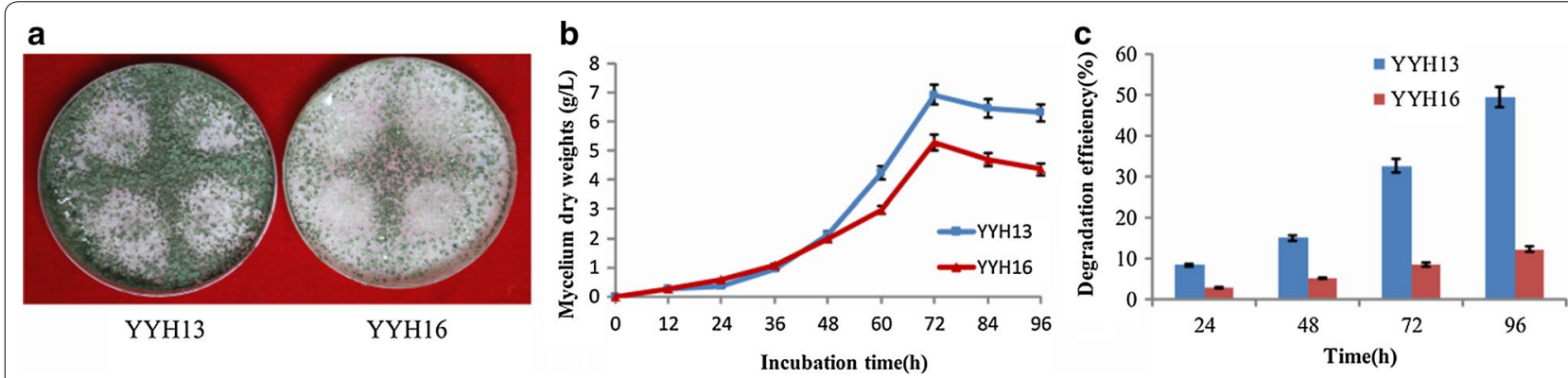

Fig. 1 Trichoderma hamatum growth natures, and anti-microorganism activity and cellulose degradation induced by $\mathrm{YYH} 13$ and $\mathrm{YYH} 16 . \mathbf{a} 72 \mathrm{~h}$ cultured Trichoderma hamatum in PDA plate. b Growth curves of Trichoderma hamatum. c Filter paper degradation by YYH13 and YYH16 strains. All analysis were performed in triplicate. The different letters indicate statistical differences between the different assays (P < 0.05) 
Table 1 Sequencing data size and output quality in YYH13 and YYH16

\begin{tabular}{|c|c|c|c|c|}
\hline Type & YYH13 Raw data & YYH13 Clean data & YYH16 Raw data & YYH16 Clean data \\
\hline Number of reads & $62,431,080$ & $58,834,452$ & $20,861,707$ & $19,051,316$ \\
\hline Data size & $12,486,216,000$ & $11,766,890,400$ (94.24\%) & $4,172,341,400$ & $3,810,263,200$ (91.32\%) \\
\hline N of fq1 & $0.00 \%$ & $0.00 \%$ & $0.02 \%$ & $0.01 \%$ \\
\hline$N$ of fq2 & $0.01 \%$ & $0.00 \%$ & $0.06 \%$ & $0.00 \%$ \\
\hline Low qual base of fq1: $(\leq 5)$ & $2.73 \%$ & $0.90 \%$ & $4.13 \%$ & $1.61 \%$ \\
\hline Low qual base of fq2: $(\leq 5)$ & $5.07 \%$ & $1.46 \%$ & $6.79 \%$ & $1.88 \%$ \\
\hline Q20 of fq1 & $95.93 \%$ & $98.03 \%$ & $93.11 \%$ & $96.21 \%$ \\
\hline Q20 of fq2 & $92.60 \%$ & $96.63 \%$ & $90.70 \%$ & $95.80 \%$ \\
\hline Q30 of fq1 & $91.76 \%$ & $94.25 \%$ & $85.60 \%$ & $89.43 \%$ \\
\hline Q30 of fq2 & $87.71 \%$ & $91.87 \%$ & $83.15 \%$ & $88.23 \%$ \\
\hline GC of fq1 & $45.24 \%$ & $45.04 \%$ & $45.14 \%$ & $44.86 \%$ \\
\hline GC of fq2 & $45.10 \%$ & $44.92 \%$ & $45.04 \%$ & $44.76 \%$ \\
\hline Error of fq1 & $0.03 \%$ & $0.03 \%$ & $0.05 \%$ & $0.04 \%$ \\
\hline Error of fq2 & $0.04 \%$ & $0.03 \%$ & $0.06 \%$ & $0.04 \%$ \\
\hline Discarded reads related to $\mathrm{N}$ and low qual & $5.76 \%$ & & $8.68 \%$ & \\
\hline
\end{tabular}

Table 2 Genome assembly and annotation statistics of YYH13, YYH16, and GD12

\begin{tabular}{|c|c|c|c|}
\hline & YYH13 & YYH16 & GD12 \\
\hline Scaffolds N50 & $578,201 \mathrm{bp}$ & $41,655 \mathrm{bp}$ & $42,825 \mathrm{bp}$ \\
\hline Scaffolds N90 & $113,623 \mathrm{bp}$ & 9276 bp & $10,787 \mathrm{bp}$ \\
\hline Number of scaffolds & 608 & 2550 & 1637 \\
\hline Contig N50 & $79,575 \mathrm{bp}$ & $9684 \mathrm{bp}$ & $2655 \mathrm{bp}$ \\
\hline Contig N90 & $20,512 b p$ & 177 bp & $1259 \mathrm{bp}$ \\
\hline Total size (scaffolds) & $38,930,246 \mathrm{bp}$ & $38,920,148$ bp & $36,656,850 \mathrm{bp}$ \\
\hline Total size (contig) & $38,928,694 \mathrm{bp}$ & 43,641,621 bp & $37,949,230 \mathrm{bp}$ \\
\hline No. of large scaf (>1 kb) & 462 & 1918 & 1609 \\
\hline $\begin{array}{l}\text { No. of large contig } \\
(>1 \mathrm{~kb})\end{array}$ & 1144 & 7564 & 9830 \\
\hline $\mathrm{G}+\mathrm{C}$ content & $47.19 \%$ & $47.93 \%$ & $48.28 \%$ \\
\hline N rate & $0.00 \%$ & $0.25 \%$ & $0.62 \%$ \\
\hline $\begin{array}{l}\text { Number of CEGs identi- } \\
\text { fied }\end{array}$ & $242(97.58 \%)$ & $241(97.18 \%)$ & $238(95.97 \%)$ \\
\hline $\begin{array}{l}\text { Total protein coding } \\
\text { genes }\end{array}$ & 11,302 & 11,758 & 11,203 \\
\hline $\begin{array}{l}\text { Total gene lengths (exon } \\
\text { and intron) }\end{array}$ & $19,416,112$ & $18,964,664$ & $18,415,061$ \\
\hline Total exon count & 31,674 & 32,404 & 33,973 \\
\hline Average exon length & 542.43 & 518.89 & 457.30 \\
\hline $\begin{array}{l}\text { Average exon count per } \\
\text { gene }\end{array}$ & 2.80 & 2.76 & 3.03 \\
\hline Total introns & 20,372 & 20,646 & 22,770 \\
\hline Average intron length & 109.72 & 104.16 & 126.44 \\
\hline $\begin{array}{l}\text { Average introns per } \\
\text { gene }\end{array}$ & 1.80 & 1.76 & 2.03 \\
\hline Average peptide length & 506.27 & 477.38 & 462.27 \\
\hline
\end{tabular}

the 92 rDNA Trichoderma sequences previously identified $[25,26]$ showed that YYH13 and YYH16 cluster with known T. hamatum, species (Fig. 3a). Similarly, according to three protein coding genes, Tef-1, Cal-1, and Chi18-5, the T. hamatum, species cluster together (Fig. 3b). This analysis further confirmed that YYH13 and YYH16 are strains of the T. hamatum species.

\section{Genome annotations of YYH13 and YYH16}

To evaluate the completeness of the assembled genomes, we performed a CEGMA (Parra et al. [26]) showed that both YYH13 and YYH16 identified more than 97\% of all of the CEGs (complete and partial) (Table 2), higher than that for the published T. hamatum GD12, which only identified $95.97 \%$. Thus, our genome assemblies of the two T. hamatum strains YYH13 and YYH16 are of good quality. We annotated the genomes for protein coding genes using GeneMark-ES and identified 11,316 and 11,755 genes in YYH13 and YYH16, respectively. The previous T. hamatum genome (GD12) was annotated using FgeneSH [21]. To assess the comparability of the two methods, we also annotated the GD12 assembly using GeneMark-ES and compared the annotation results. FgeneSH predicted 10,760 genes, and GeneMark-ES predicted 11,031 genes, for which 10,169 (94\% of FgeneSH annotation) genes corresponded to identical annotation structures, and 46 genes were found only by FgeneSH. Thus, we conclude that the FgeneSH gene prediction was comparable to the GeneMark-ES predictions. For consistency, we used the GeneMark-ES annotations 


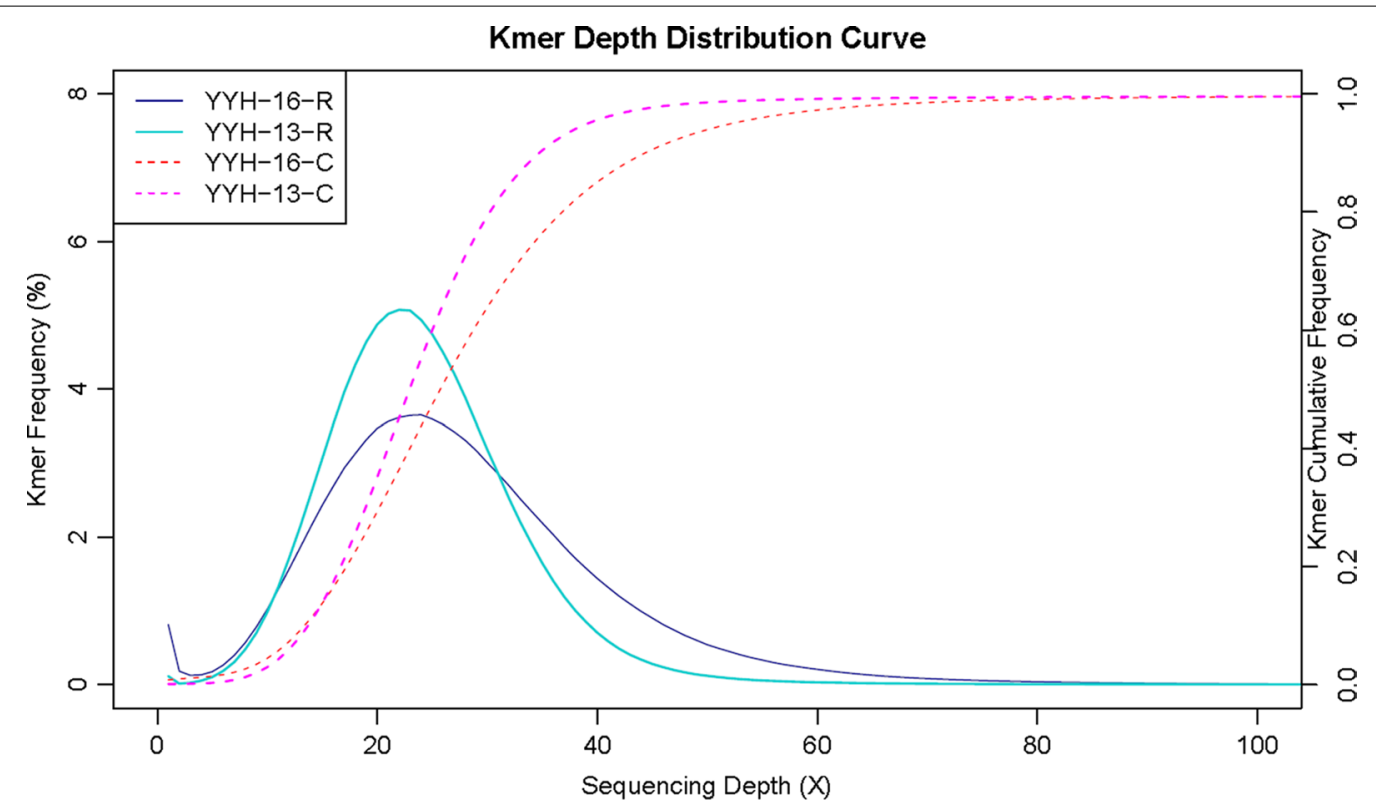

Fig. 2 17-mer analysis of YYH13, YYH16, and T. reesei QM6a. A single peak is seen around 60 in YYH13 and YYH16. The longer tail of YYH16 suggesting more repetitive content

Table 3 17-mer analysis using YYH13, YYH16, and reesei sequencing data

\begin{tabular}{llllllll}
\hline Species & Kmer & Kmer count & Kmer depth & $\begin{array}{l}\text { Genome } \\
\text { size (M) }\end{array}$ & $\begin{array}{l}\text { Revised } \\
\text { genome size (M) }\end{array}$ & $\begin{array}{l}\text { Heterozygousity } \\
\text { rate (\%) }\end{array}$ & Repeat (\%) \\
\hline YYH13 & 17 & $2,603,966,477$ & 60.15 & 43.29 & 43.29 & 0.35 & 30.13 \\
YYH16 & 17 & $2,942,740,366$ & 59.05 & 49.83 & 49.82 & 0.51 & 46.59 \\
REESEI & 17 & $959,718,356$ & 20.51 & 46.79 & 43.45 & 0.29 & 30.34 \\
\hline
\end{tabular}
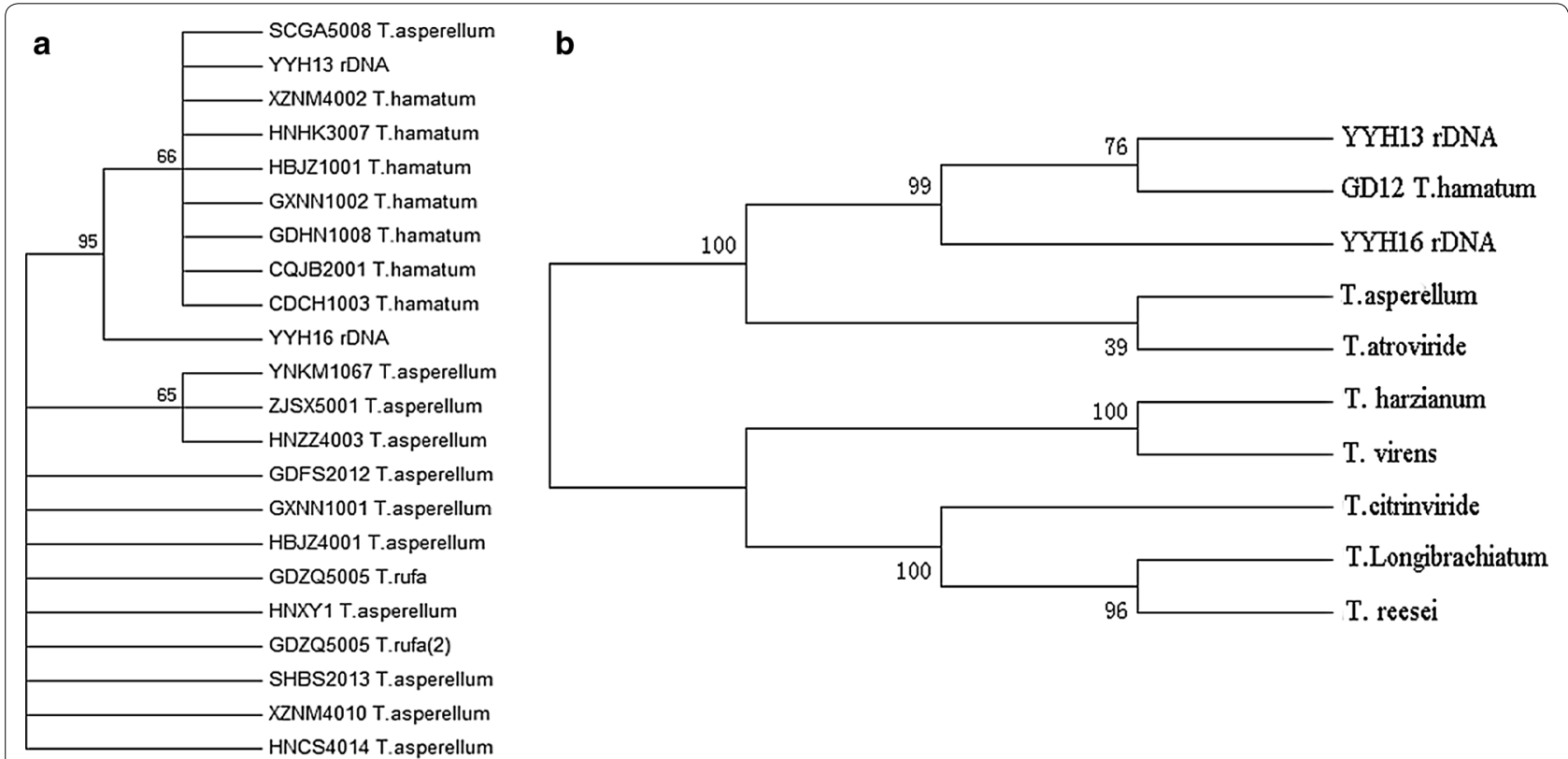

Fig. 3 Phylogenetic tree analysis. a Phylogenetic tree using ITS1-ITS2 sequences. b Phylogenetic tree using Tef-1, Cal-1, and Chi18-5 
Table 4 Repetitive element annotation in YYH13, YYH16, and GD12

\begin{tabular}{|c|c|c|c|}
\hline Type & YYH13 & YYH16 & GD12 \\
\hline Repeat length & 571,404 bp & $614,668 \mathrm{bp}$ & $478,638 \mathrm{bp}$ \\
\hline$\%$ of genome & $1.47 \%$ & $1.58 \%$ & $1.31 \%$ \\
\hline $\begin{array}{l}\text { DNA transpo- } \\
\text { sons }\end{array}$ & $\begin{array}{c}70,804 \mathrm{bp} \\
(0.18 \%)\end{array}$ & $\begin{array}{c}27,383 \mathrm{bp} \\
(0.07 \%)\end{array}$ & $54,399 \mathrm{bp}(0.15 \%)$ \\
\hline LINE & 3710 bp (0.01\%) & $\begin{array}{c}17,140 \mathrm{bp} \\
(0.04 \%)\end{array}$ & 7052 bp (0.02\%) \\
\hline SINE & 0 bp (0\%) & 0 bp (0\%) & 0 bp (0\%) \\
\hline LTR & $\begin{array}{c}43,448 \mathrm{bp} \\
(0.11 \%)\end{array}$ & $\begin{array}{c}44,856 \mathrm{bp} \\
(0.12 \%)\end{array}$ & 38,856 bp (0.11\%) \\
\hline Satellites & 7770 bp (0.02\%) & $7550 \mathrm{bp}(0.02 \%)$ & 6257 bp (0.02\%) \\
\hline Simple repeats & $\begin{array}{c}402,017 \mathrm{bp} \\
(1.03 \%)\end{array}$ & $\begin{array}{c}432,358 \mathrm{bp} \\
(1.11 \%)\end{array}$ & $\begin{array}{c}324,187 \mathrm{bp} \\
(0.88 \%)\end{array}$ \\
\hline Low complexity & $\begin{array}{c}78,531 \mathrm{bp} \\
(0.20 \%)\end{array}$ & $\begin{array}{c}83,574 \mathrm{bp} \\
(0.21 \%)\end{array}$ & 66,153 bp (0.18\%) \\
\hline
\end{tabular}

Table 5 Non-coding RNA annotation in YYH13, YYH16, and GD12

\begin{tabular}{lccc}
\hline RNA type & YYH13 & YYH16 & GD12 \\
\hline 5S_rRNA & 56 & 53 & 49 \\
5_8S_rRNA & 1 & 0 & 0 \\
SSU_rRNA_eukarya & 1 & 0 & 0 \\
SnoRNA & 20 & 20 & 19 \\
Splicesomal RNA & 11 & 14 & 10 \\
Fungi_SRP & 1 & 1 & 1 \\
Intron_gpl & 1 & 0 & 0 \\
RNase_MRP & 1 & 1 & 1 \\
Total & 92 & 89 & 80
\end{tabular}

for all of the subsequent analyses. The average gene structures (gene size, exon size, and intron size) were also similar among the T. hamatum species (Table 2).

We then annotated repetitive elements using RepeatModeler and RepeatMasker and found $1.47 \%$ repetitive elements for YYH13 and 1.58\% for YYH16, with the most contribution due to simple repeats (Table 4). In terms of transposable elements, T. hamatum had similar levels to $T$. atroviridae $(0.49 \%)$, T. reesei $(0.57 \%)$, and $T$. virens $(0.48 \%)$ [22]. Finally, the non-coding RNA (ncRNA) annotation tracks were an important contribution to the genome-wide annotation datasets of both YYH13, YYH16, and GD12, not only contributing to the protein-based annotation but also helping to identify annotation errors (Table 5).

Identifying functionally important genes through selection pressure analysis

Selection pressure is an important source for genetic differences that may confer phenotypic differences. By examining the nonsynonymous and synonymous substitution rates of all of the one-to-one ortholog pairs of YYH13, YYH16, and GD12, we found that the majority of the genes $(>98 \%)$ exhibited $\mathrm{Ka} / \mathrm{Ks}<1$, suggesting that most of the orthologs are highly conserved in evolution (Additional file 1). Nevertheless, we found that 131 genes between YYH13 and YYH16, 146 genes between GD12 and YYH16, and 154 genes between GD12 and YYH13 corresponded to $\mathrm{Ka} / \mathrm{Ks}$ value greater than 1 . To screen for YYH13 genes that underwent positive selection, we selected genes that satisfied positive selection criteria between YYH13 and the other two genomes but neutral or purifying selection between YYH16 and GD12. Interestingly, we found 13 genes that satisfied the above condition, one of which (GB7226_YYH13) encodes a putative subtilisin protease, which has been shown to be an exoprotease during cellulose metabolism [23, 24].

Notably, the difference between the percentages of non-synonymous mutations was retained among the three strains, which may be due to the different physiological conditions used for the selection of the strains. The selection could have been stronger for YYH13, resulting in positive selection, and thus preferential retention of non-synonymous SNVs. Moreover, Darwinian selection was tested [27], and the results showed that positive selection drove the evolution of sequences leading to well-known $\beta$-glucosidases involved in lignocellulose. Indeed, this study found that YYH13 has 13 genes with $\mathrm{Ka} / \mathrm{Ks}>1$, there is an obvious selection pressure will lead to $\beta$-glucosidase gene (YYH1311079) production diversity and genetic and functional difference.

\section{Synteny analysis of T. hamatum strains}

Because YYH13 and YYH16 were isolated from the same location, we expected their genomic structures to be highly similar. We examined synteny relationships using orthocluster based on the gene annotations and oneto-one orthologous relationships identified by Inparanoid, and we found that YYH13 and YYH16 exhibited high synteny levels, whereas YYH16 and GD12 showed the least synteny (Fig. 4). This result is in agreement with the phylogenetic analysis that revealed YYH16 is slightly more distant to YYH13 and GD12, suggesting that YYH16 may have undergone genome rearrangement that caused a decrease in its lignocellulose degradation activity.

As previously argued, high synteny between organisms indicates evolutionary relatedness. Therefore, we expect to find more genes with high synteny than between more distant pairs of species. However, Berlin [28] argued that gene transposition, insertions, deletions, and duplications and rearrangements of chromosome fragments destroy synteny. We found that although some characteristics of 

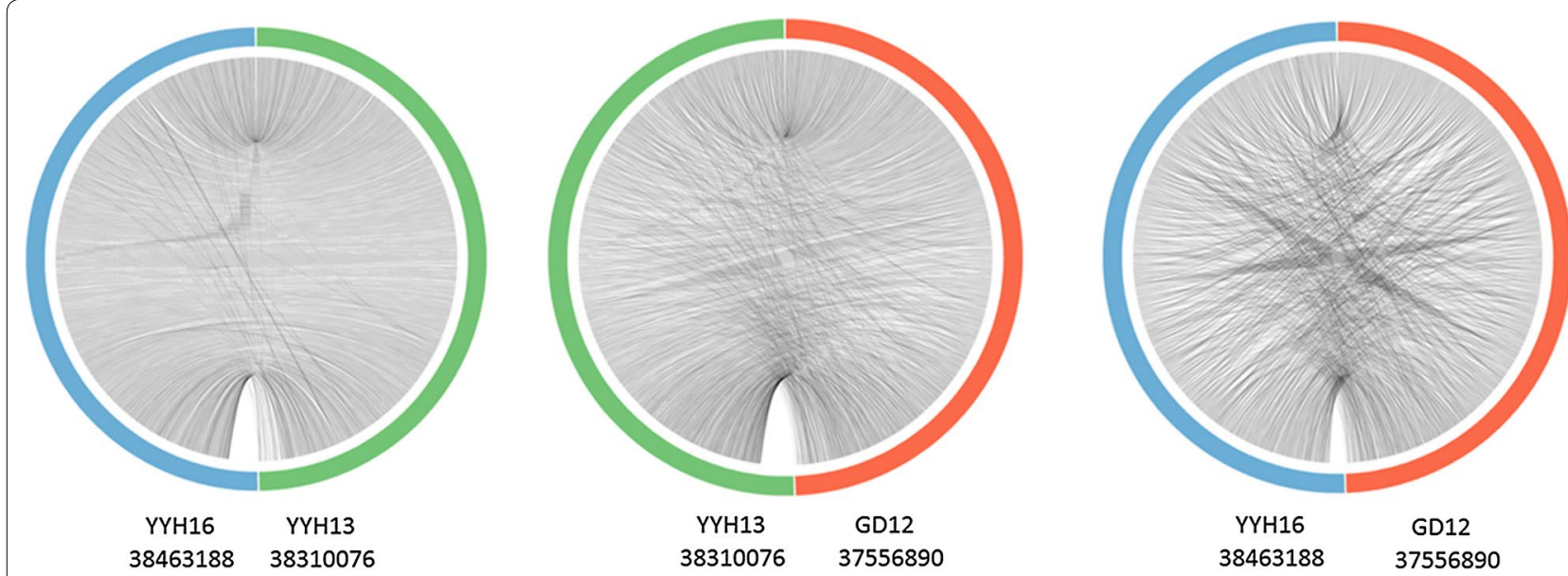

Fig. 4 Circos plot of synteny relationships between two genome assemblies. The synteny is based on imperfect synteny blocks identified by Orthocluster. The contigs for the relationships are ordered by the assemblies on the left. The number below the strain name is the genome size with contigs that show one-to-one orthologous relationships. Each line in the centre of the circos plot represent one synteny block between the two assemblies. A more ordered lines indicates higher level of synteny conservation while a more complex banding pattern represent less synteny conservation

the tri/TRI cluster have been conserved during evolution of YYH13 and YYH16, the cluster has undergone marked changes, including gene loss or gain, gene rearrangement, and divergence of gene function. In comparison, previous studies [29] have indicated that syntenic gaps in other genomes are enriched in genes that are important for species difference attributes. Although the mechanism and specific biological functions of YYH13 gene duplication have not be clarified, Ambro [30] showed that gene evolution is accelerated to derive new functional genes after gene duplication.

\section{Strain-specific genes in YYH13, YYH16 and GD12}

One way for obtaining a new phenotype is by acquiring new genes [31]. To examine this possibility, we identified strain-specific genes in YYH13, YYH16, and GD12 by examining orthologous relationships between gene annotations. Although over $90 \%$ of the orthologous genes are shared among all three genomes, a small fraction of genes show genome specificity. Based on the GeneMark-ES annotation, we identified 270 genes in YYH13, 808 genes in YYH16, and 508 genes in GD12 that are strain-specific (Fig. 5). We employed a gene revision procedure to ensure that these genes were not identified due to technical errors in gene annotation or inadequate genome assembly. After revision, we found 172 genes in YYH13, 655 in YYH16, and 320 in GD12 that we believe are genome difference with high confidence. However, the majority of these genes do not possess any known functional annotation and only match hypothetical genes in other species (Additional file 2). Of the genes that can be annotated, YYH13 possess a gene with a subtilase domain

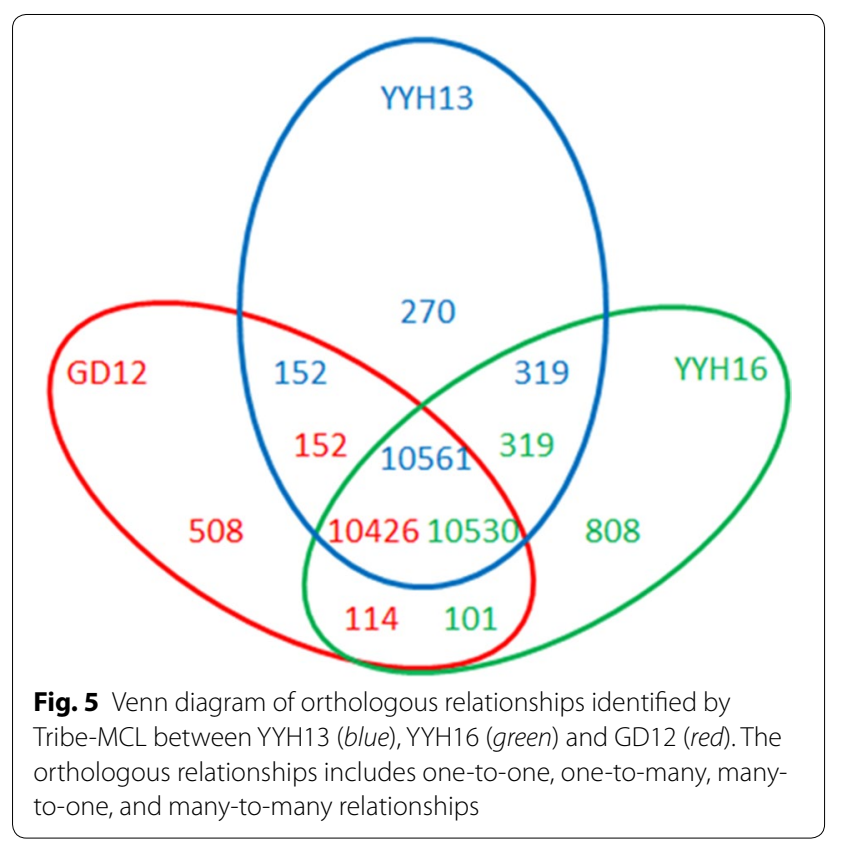

and another gene with an alpha/beta hydrolase domain, both of which are domains found in many peptidases. In YYH16, we found three genes with helicase domains and two genes with transporter function. The comparison of gene functions in these genome difference genes showed that the functions between the genomes are quite different, suggesting that YYH13 and YYH16 may have undergone strain difference evolution.

In this study, the rate of synonymous substitutions in the YYH13 gene was found to be very small, which generally 
occur in the process of evolution during a large-scale genome duplication event, indicating that recent duplication has played an important role in the creation of synonymous substitutions. At the same time, the purification selection pressure after YYH13 difference gene duplication was less than gene duplication of communalism, which suggests that the difference of the difference genes is more likely to produce functional variations. Nevertheless, difference genes of YYH16 may be due to functional redundancy, which contribute less to degrading lignocellulose. Similarly, the instability of transposable elements may lead to YYH16 gene rearrangement, and distribution imbalances of insertion sequences may also affect its evolution, leading to difference expression differences among strains.

\section{Proteases gene family comparison}

Proteases are important enzymes that digest and cleave peptides at various levels of metabolism. However, proteases of Trichoderma have not been systematically compared at the whole-genome scale. Here, we systematically annotated protease genes in the YYH13, YYH16, and GD12 genomes using the MEROPS database [32]. A large portion (9\%) of the secreted protein of T. harzianum was identified as proteases when grown on cellulose [33], suggesting its importance in the cellulose degradation process. We annotated the gene and identified 58 protease families in the YYH13 and YYH16 genomes. Of these families, 26 initially showed gene family expansion or contraction. After gene revision, we found 15 gene families that still differ between YYH13 and YYH16 (Table 6).
Gene families that have more members in YYH13 include all of the metallopeptidases, whose activity requires metal ions, whereas those in YYH16 are more varied. Genomes show expansions in carboxypeptidases, which are involved in the degradation of barley cell walls by $T$. viride [34].

However, carboxypeptidases in the Trichoderma species with no known identified, thus the roles of the carboxypeptidases of $T$. hamatum in these interactions are still unknown. The proteases of Trichoderma spp. and their biocontrol roles have been previously reported [35]. Interestingly, this work describes a protease gene family analysis of T. hamatum focusing on biomass degrading activity. Proteases have evolved to utilize different mechanisms for proteolysis [36, 37]. Further studies are needed to understand what causes $T$. hamatum to produce primarily protease-degrading enzymes when grown in the presence of cellulose.

\section{CAZyme gene family comparison}

CAZymes are families of enzymes that degrade, modify, or generate glycosidic bonds [38]. These enzymes, especially those of hydrolytic enzymes, have been associated with the mycoparasitism of Trichoderma [39]. Of the 140 CAZyme gene families that we annotated using dbCAN, we initially found 36 families that exhibited gene family expansion or contraction between YYH13 and YYH16. To ensure that the observed differences were not due to technical errors from annotation or genome assembly, we employed the same gene annotation revision to recover any gene

Table 6 Protease family showing difference between YYH13 and YYH16

\begin{tabular}{|c|c|c|c|c|c|}
\hline Family & YYH13 & YYH16 & GD12 & Function & $\begin{array}{l}\text { Location } \\
\text { of activity }\end{array}$ \\
\hline M04 & 2 & 1 & 1 & Thermolysin & Endo \\
\hline M20 & 3 & 2 & 2 & Carboxypeptidase & ExO \\
\hline M24 & 10 & 9 & 9 & x-Pro dipeptidase & Exo \\
\hline M43 & 4 & 3 & 2 & Cytophagalysin, pappalysin & Endo \\
\hline C14 & 2 & 3 & 2 & Caspases & Endo \\
\hline C19 & 10 & 11 & 9 & Ubiquitin peptidase & Endo \\
\hline $\mathrm{C} 26$ & 6 & 8 & 7 & Gamma-glutamyl hydrolase & Endo \\
\hline C85 & 0 & 1 & 1 & Deubiquitinylating peptidases & Endo \\
\hline G01 & 4 & 5 & 4 & Scytalidoglutamic peptidase & Endo \\
\hline M28 & 10 & 11 & 10 & Aminopeptidases, carboxypeptidases & \\
\hline M38 & 6 & 8 & 8 & Isoaspartyl dipeptidase & Endo \\
\hline M54 & 0 & 1 & 1 & Archaelysin & Exo \\
\hline S10 & 5 & 6 & 4 & Carboxypeptidase Y & \\
\hline S33 & 10 & 14 & 12 & Prolyl aminopeptidase & EXO \\
\hline S53 & 11 & 12 & 12 & Sedolisin & Endo \\
\hline
\end{tabular}

Location of activity indicates whether the family is an endoprotease or exoprotease

Enzymes: $C$ cysteine proteases, $G$ glutamic proteases, $M$ metalloproteases, $S$ serine proteases 
annotation that may have been missed. After our gene annotation revision, we found 31 gene families that still showed differences between YYH13 and YYH16, including four CAZyme auxiliary enzyme (AA) families, five carbohydrate-binding modules (CBM) families, three carbohydrate esterase (CE) families, 13 glycoside hydrolase (GH) families, and six glycosyl transferase (GT) families (Additional file 3). In general, YYH13 possesses more GH family members than YYH16. In fact, 10 of the 13 expanded GH family members are in YYH13, including many families of chitinases, glucosidases, galactosidases, and glucanases (Table 7). However, the gene family expanded in
YYH16 functions in acetylgalactosaminidase, xylanase and $\alpha$-glucosidase. All of these $10 \mathrm{GH}$ families lacked clear orthologs in YYH16. The phylogenetic analysis indicated that the additional genes in YYH13 are primarily due to gene family expansion and only three families (GH1, GH3, and GH55) suggest gene family contraction in YYH16 (Fig. 6). The other three families with more members in YYH16 showed YYH16 gene family expansion in GH109 and YYH13 gene family contraction in GH30.

Of the GH families, those containing $\beta$-glucosidases include GH1, GH3, GH5, GH9, GH30 and GH116. The GH1, GH5, and GH30 $\beta$-glucosidases fall in GH Clan A,

Table 7 CAZyme families that show difference between YYH13 and YYH16

\begin{tabular}{|c|c|c|c|c|}
\hline Family & YYH13 & YYH16 & GD12 & Function \\
\hline AA11 & 4 & 3 & 4 & Copper-dependent lytic polysaccharide monooxygenases \\
\hline AA4 & 2 & 1 & 1 & Vanillyl-alcohol oxidases \\
\hline CBM13 & 7 & 6 & 7 & Cellulose-binding \\
\hline CBM18 & 13 & 11 & 9 & Chitin-biding \\
\hline CBM67 & 3 & 2 & 2 & L-Rhamnose binding \\
\hline CE1 & 21 & 18 & 20 & Esterases \\
\hline GT31 & 5 & 4 & 5 & Acetylglucosaminyltransferase \\
\hline GT35 & 2 & 1 & 1 & Glycogen or starch phosphorylase \\
\hline GT69 & 4 & 3 & 3 & a-1,3-Mannosyltransferase \\
\hline $\mathrm{GH} 1$ & 4 & 3 & 3 & $\beta$-Glucosidases, $\beta$-galactosidases \\
\hline $\mathrm{GH} 18$ & 31 & 30 & 26 & Chitinase, xylanase inhibitor \\
\hline $\mathrm{GH} 20$ & 4 & 3 & 3 & $\begin{array}{l}\text { Exo-acting } \beta \text {-N-acetylglucosaminidases, } \beta \text {-N-acetylgalactosamindase, } \\
\beta \text {-6-SO3-N-acetylglucosaminidases }\end{array}$ \\
\hline $\mathrm{GH} 3$ & 19 & 17 & 18 & $\begin{array}{l}\text { Exo-acting } \beta \text {-D-glucosidases, } \alpha \text {-L-arabinofuranosidases, } \beta \text {-D-xylopyranosidases, } \\
\quad \mathrm{N} \text {-acetyl- } \beta \text {-D-glucosaminidases }\end{array}$ \\
\hline $\mathrm{GH} 35$ & 3 & 2 & 2 & $\beta$-Galactosidases \\
\hline $\mathrm{GH} 43$ & 7 & 6 & 6 & $\begin{array}{l}\text { L-arabinofuranosidases, endo-a-L-arabinanases, } \beta \text {-D-xylosidases, } \\
\text { exo a-1,3-galactanase }\end{array}$ \\
\hline GH55 & 10 & 9 & 8 & Exo- $\beta$-1,3-glucanases, endo- $\beta$-1,3-glucanases \\
\hline GH76 & 9 & 8 & 8 & a-Mannanases \\
\hline GH78 & 5 & 4 & 4 & L-Rhamnosides \\
\hline GH88 & 2 & 1 & 2 & $\mathrm{~d}-4,5$-Unsaturated $\beta$-glucuronyl hydrolase \\
\hline AA1 & 4 & 5 & 2 & Ferroxidase \\
\hline AA5 & 1 & 2 & 1 & Galactose oxidase, glyoxal oxidase \\
\hline CBM21 & 1 & 2 & 0 & Granular starch-binding \\
\hline CBM42 & 2 & 3 & 2 & Arabinofuranose binding \\
\hline CE3 & 3 & 4 & 2 & Acetyl xylan esterase \\
\hline CE5 & 8 & 9 & 8 & Acetyl xylan esterase, cutinase \\
\hline GT2 & 10 & 11 & 10 & Cellulose synthase, chitin synthase \\
\hline GT25 & 0 & 1 & 0 & Lipopolysaccharide $\beta$-1,4-galactosyltransferase \\
\hline GT4 & 5 & 6 & 4 & Sucrose synthase, a-glucosyltransferase \\
\hline GH109 & 17 & 18 & 13 & a-N-Acetylgalactosaminidase \\
\hline $\mathrm{GH} 30$ & 5 & 6 & 6 & Endo- $\beta-1,4-x y l a n a s e, \beta-g l u c o s i d a s e$ \\
\hline $\mathrm{GH} 4$ & 0 & 1 & 0 & a-Glucosidase, a-galactosidase \\
\hline
\end{tabular}

Function is based on CAZY database annotation

Enzymes: GH glycoside hydrolase, GT glycosyltransferase, CBM carbohydrate-binding module, $A A$ auxiliary activity, $C E$ carbohydrate esterase 

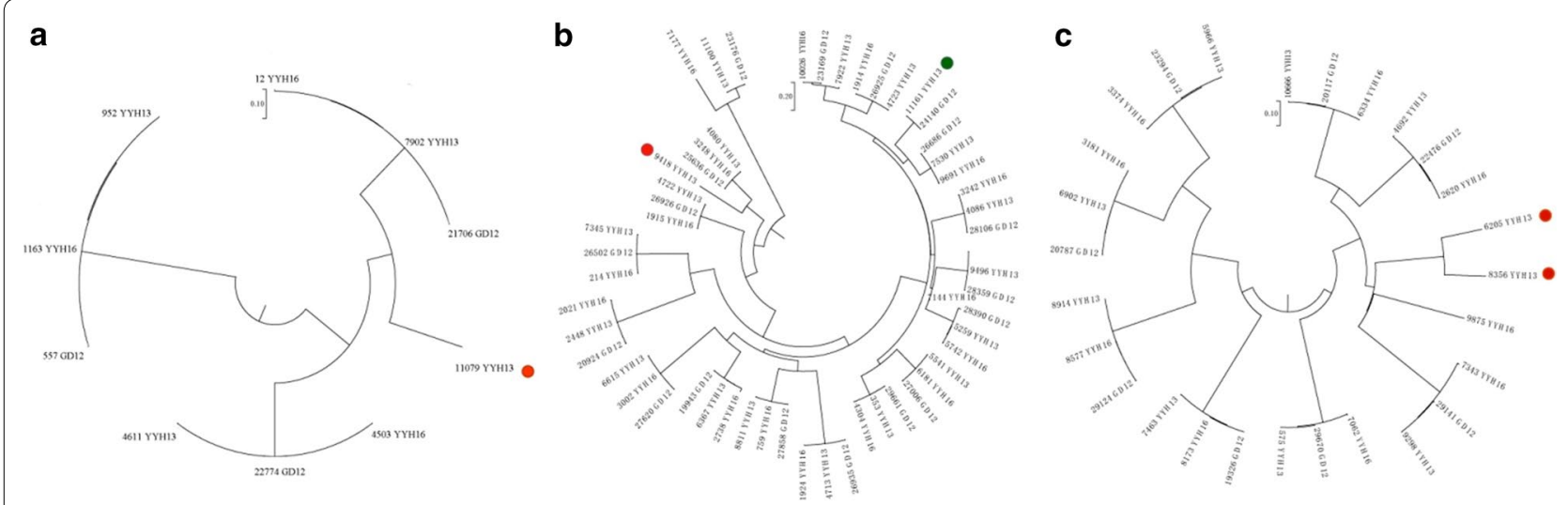

Fig. 6 Examples of gene families with gene family expansion in YYH13 or gene family contraction in YYH16. The trees were constructed from a $\mathrm{GH} 1, \mathbf{b} \mathrm{GH} 3$, and $\mathbf{c} \mathrm{GH} 55$ with genes found in $\mathrm{YYH} 13, \mathrm{YYH} 16$, and GD12. The red dots indicate gene the expanded genes in $\mathrm{YYH} 13$ and the green dot indicate sub-family with missing YYH16 likely due to gene family contraction

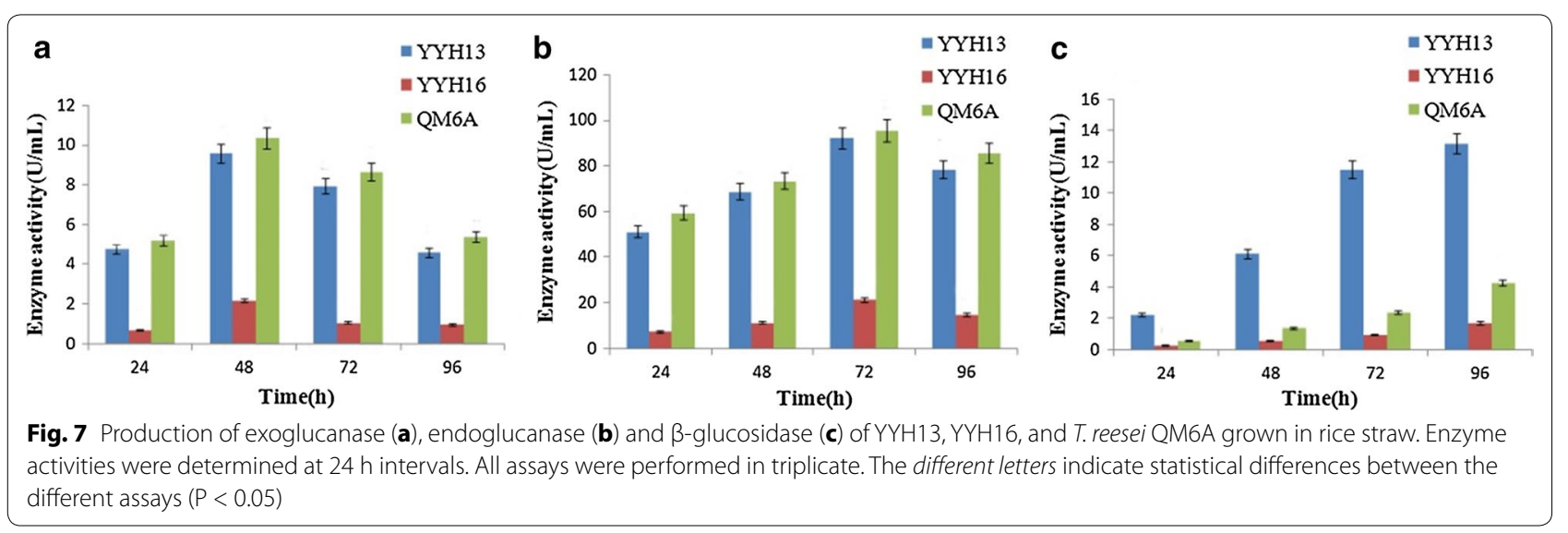

which consists of proteins with $(\beta / \alpha)_{8}$ barrel structures. In contrast, the active site of GH3 enzymes comprises two domains, while GH9 enzymes have $(\alpha / \alpha)_{6}$ barrel structures. The mechanism by which GH1 enzymes recognize and hydrolyze substrates with different specificities remains an area of intense study [40]. For the rational design of improved biocatalysts, it is advantageous to work with a well-characterized enzymes or at least enzymes from well-studied families, such as the GH1. These results are consistent with the fact that GH1 enzymes have a large range of potential substrates and specificities, particularly regarding aglycone. To examine whether the activity is indeed higher in YYH13, we subjected YYH13, YYH16, and T. reesei QM6a to enzymatic tests on rice straw in exoglucanase, endoglucanase, and $\beta$-glucosidase. Our results showed that YYH13 was several-fold higher in activity than YYH16 (Fig. 7).

The saprotrophic species $T$. reesei is a model for studying Trichoderma physiology [41]. Comparative genomics showed that YYH13 has a bigger genome than the mycoparasitic species $T$. reesei, suggesting that gene expansion events have occurred in an ancestor of YYH13. YYH16 is a close relative of YYH13, although YYH13 has more lignocellulose degrading related genes, including CAZymes, than YYH16, suggesting that additional saprotrophic gene expansion events occurred in YYH13 after divergence from YYH16. In summary, T. reesei is an efficient producer of cellulases and hemicellulases and is used as the major industrial resource of these enzymes [42]. YYH13 is also an efficient cellulase producer. Furthermore, comparing cellulolytic enzymes and hemicellulolytic enzymes indicates that the number of these genes did not reduce but was increased in YYH13. The increase in lignocellulose degrading ability is affiliated with the increase in the number of lignocellulose degrading-related genes. Saprotrophy of plant biomass and the high efficiency of cellulolytic enzymes and hemicellulolytic enzyme production suggest that these enzymes may have been optimized to improve specific activities or expression levels in YYH13. In addition, chitinases, 
glucosidases, galactosidases, and glucanases are subject to stronger positive selection pressure in YYH13, implying that these enzymes may also play crucial roles in lignocellulose degradation.

The omics data analysis and experimental results showed that YYH13 genome expansion is affected by environmental conditions. To adapt to the specific requirements of the host environment, more genes of YYH13 have been differentiated and have formed multiple gene families. The Red Queen hypothesis [43, 44] considers that microorganisms are constantly faced with a contradiction between evolution and adaptation in the biological environment such that their genomes must be modified and transformed to overcome the contradiction. Phylogenetic analysis revealed that YYH13 mutations function significantly stronger than the effect of homologous recombination and that the classification characteristics and genealogy of YYH13 and YYH16 were shaped by these mutations. Consequently, given the differences in the genomes of strains isolated from the same area and phylogenetic classifications among different geographical regions, notwithstanding the environmental and geographic distribution distance factors, there may be other factors driving the evolution of YYH13, YYH16, and GD12 genomes and their population difference.

\section{Expression assay of $\mathrm{GH} 1$ genes in $\mathrm{YYH} 13$ and $\mathrm{YYH} 16$}

As shown in Fig. 8, gene expression levels for cellobiose as a carbon source were higher in YYH13 than YYH16. Minimal glucose but no cellobiose was detected in the YYH13 culture, suggesting that cellobiose was readily hydrolyzed to glucose by extracellular $\beta$-glucosidases rather than transported into cells. The expression levels of six genes were substantially higher in YYH13 than in YYH16 from 4 to $12 \mathrm{~h}$. The maximum expression levels of YYH137902 (YYH1612), YYH13952 (YYH1611163) and YYH134611 (YYH164503) in YYH13 were three times, four times and 10 times higher than that in YYH16, respectively (Fig. 8). Moreover, the expression of YYH1311079 was notably higher than other genes when grown on cellobiose in YYH13, indicating stronger degradation levels of cellobiose.
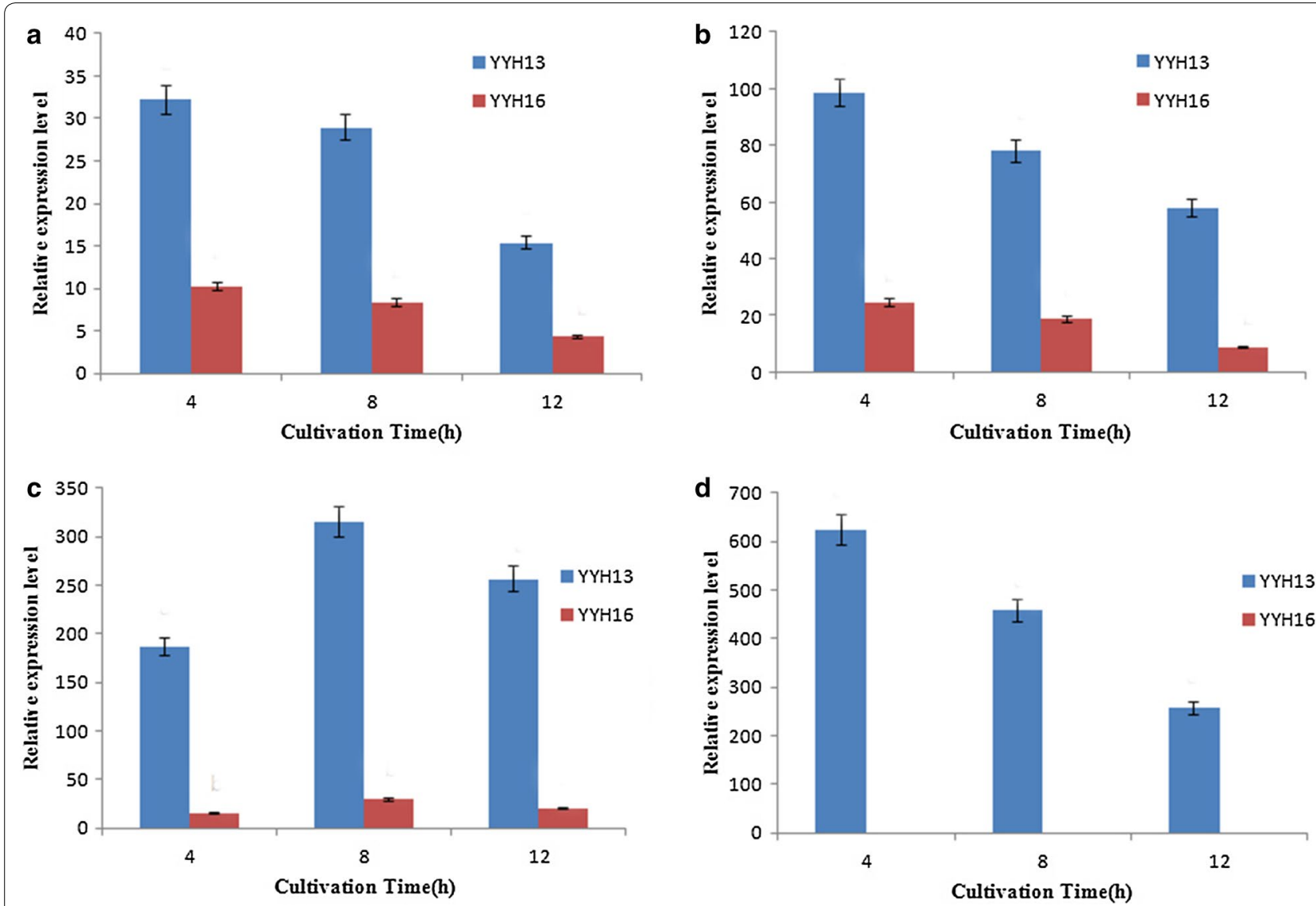

Fig. 8 Effects of cellobiose on YYH137902 and YYH1612 (a), YYH13952 and YYH1611163 (b), YYH134611 and YYH164503 (c), YYH1311079 (d) betaglucosidase genes expression in YYH13 (T. hamatum) and YYH16 (T. hamatum). Genes relative expression levels were determined at different time intervals. All analysis were performed in triplicate. The different letters indicate statistical differences between the different assays $(P<0.05)$ 
In contrast, we found that the activity of $\beta$-glucosidase in YYH13 was significantly higher than QM6A (Fig. 7c). In fact, $\beta$-glucosidase is an important component of the cellulase enzyme system that not only participates in cellulose degradation but also plays a key role in hydrolyzing cellulose to fermentable glucose by relieving the inhibition of exoglucanase and endoglucanase from cellobiose. However, it is difficult for T. reesei to efficiently convert cellobiose to glucose due to the lack of $\beta$-glucosidase, although it is a good producer of cellulase [24].

Cellobiose, which is an intermediate product, is also a strong inhibitor of endoglucanase and exoglucanase and is one of the key bottlenecks in enzymatic hydrolysis [45]. To prevent this inhibition process, the cellobiose unit must be immediately removed. $\beta$-glucosidase reduces cellobiose inhibition by hydrolyzing the disaccharide to glucose, allowing cellulolytic enzymes to function more efficiently [46]. Therefore, homologous production and evolutionary studies of the $\beta$-glucosidase gene (YYH1311079) from the biomass-degrading fungus $T$. hamatum gives new insights into the physicochemical parameters and biodiversity of this family.

\section{Cloned $Y Y H 1311079$ gene and construction of pGEX-KG/YYH1311079 expression vector}

In the present study, YYH1311079 gene fragment of about 1575 bp was cloned according to the YYH13 cDNA library by PCR (Fig. 9). After the double digestion of the recombinant plasmid with BamHI and HindIII, the result of $1 \%$ agarose gel electrophoresis of positive clones showed two specific bands. One was close to the location of plasmid before the digestion, the other had a uniform size as the target gene (Fig. 10). The result of DNA sequencing showed that the inserted fragment was $1575 \mathrm{bp}$, and when it was matched with the YYH1311079 gene sequence recorded in the YYH13 genome, the sequencing results were $100 \%$ homologous.

YYH1311079 cDNA clone was inserted in the pGEX$\mathrm{KG}$, a expression vector at BamHI and HindIII sites. Following transformation to Escherichia coli BL21 (DE3) cells, the recombinant clone was selected and propagated. The recombinant plasmid with $Y Y H 1311079$ gene insert was confirmed following the digestion with $\mathrm{BamHI}$ and HindIII which released the fragment of desired $1575 \mathrm{bp}$. Ampicillin resistance gene and ColE1 origin are provided for selection and maintenance of recombinant in E. coli.

The pGEX-KG/YYH1311079 engineered bacteria was constructed according the antibiotic resistance, colony PCR and sequencing analysis. It indicated that the expression plasmid was constructed correctly. Overall, our results will provide a valuable gene that will be explain whether $\beta$-glucosidase is a key rate-limiting enzyme

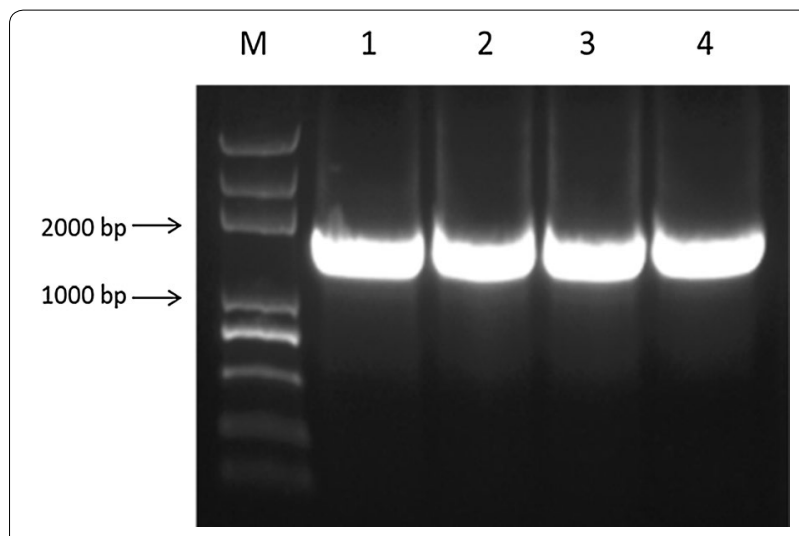

Fig. 9 Amplified products of YYH1311079 gene (MTrans2K Plus DNA Marker, 1-4 PCR products)

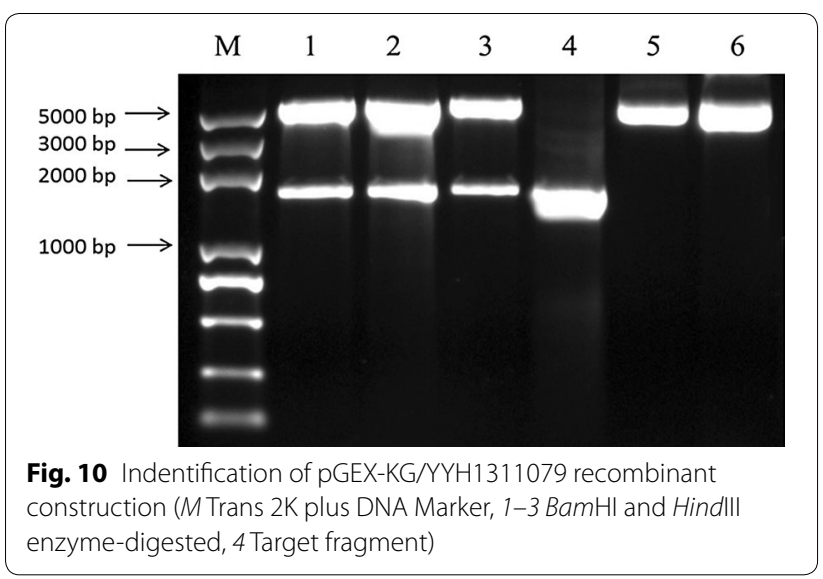

in the process of cellulose degradation. YYH13 strain whether displayed better characteristics in cellulose degradation, and showed great application potentials in ethanol production through degrading renewable lignocellulosic biomass although correlative mechanisms still need further exploration.

\section{Methods \\ Morphological analysis}

The isolates were cultured on PDA (Potato Dextrose Agar, Difco) and were incubated in normal light for 3 days at $28{ }^{\circ} \mathrm{C}$. For morphological characterization of $T$. hamatum, observations on morphology of mycelium, spore, and colonial were made using Microscopic Imaging System-MVC2000 [17].

\section{Strains growth conditions and mycelium dry weights determinations}

Mature spores of YYH13 and YYH16 strains were collected and re-suspended in sterile distilled water containing $0.05 \%$ Tween 20 (Sigma, USA). Spores were counted 
by haemacytometer. $5 \times 10^{5}$ spores of YYH13 and YYH16 strains were added to $50 \mathrm{~mL}$ PDA liquid media respectively, and cultured at $28{ }^{\circ} \mathrm{C}$ in the conditions of dark and continuous shaking. For the determination of fungal dry weights, mycelia were collected by two layers of paper filter (Whatman GF-C) after culture of 12, $24,36,48,60,72,84$ and $96 \mathrm{~h}$ respectively. Mycelia were rinsed with distilled water three times and then dried in oven at $60^{\circ} \mathrm{C}$.

\section{Strains liquid fermentation culture conditions}

YYH13 (T. hamatum), YYH16 (T. hamatum) and QM6A (T. reesei) strains at the same growth states were cultured in liquid fermentation medium $\left(\mathrm{NH}_{4} \mathrm{NO}_{3} \cdot 2 \mathrm{~g}\right.$, $\mathrm{KH}_{2} \mathrm{PO}_{4} \cdot 4 \mathrm{~g}, \mathrm{MgSO}_{4} \cdot 7 \mathrm{H}_{2} \mathrm{O} 0.3 \mathrm{~g}, \mathrm{CaCl}_{2} \cdot 2 \mathrm{H}_{2} \mathrm{O} 0.3 \mathrm{~g}$, $\mathrm{MnSO}_{4} \cdot 7 \mathrm{H}_{2} \mathrm{O} 0.007 \mathrm{~g}, \quad \mathrm{FeSO}_{4} \cdot 7 \mathrm{H}_{2} \mathrm{O} 0.005 \mathrm{~g}, \mathrm{NaCl}$ $0.1 \mathrm{~g}, 1 \%$ of rice straw, $1000 \mathrm{~mL} \mathrm{H}_{2} \mathrm{O}, \mathrm{pH} 6.0$ ) at $28{ }^{\circ} \mathrm{C}$ and while shaking at $120 \mathrm{rpm}$ for $0,24,48,72$, or $96 \mathrm{~h}$. Crude enzyme extract was obtained via centrifugation at $13,000 g \times 10 \mathrm{~min}$ at $4{ }^{\circ} \mathrm{C}$, and the supernatants were used for enzyme activity assays.

YYH13 and YYH16 strains at the same growth state were cultured in the minimal medium $\left(\mathrm{NH}_{4} \mathrm{NO}_{3} \cdot 2 \mathrm{~g}\right.$, $\mathrm{KH}_{2} \mathrm{PO}_{4} \cdot 4 \mathrm{~g}, \mathrm{MgSO}_{4} \cdot 7 \mathrm{H}_{2} \mathrm{O} 0.3 \mathrm{~g}, \mathrm{CaCl}_{2} \cdot 2 \mathrm{H}_{2} \mathrm{O} 0.3 \mathrm{~g}$, $\mathrm{MnSO}_{4} \cdot 7 \mathrm{H}_{2} \mathrm{O} 0.007 \mathrm{~g}, \mathrm{FeSO}_{4} \cdot 7 \mathrm{H}_{2} \mathrm{O} 0.005 \mathrm{~g}, \mathrm{NaCl} 0.1 \mathrm{~g}$, peptone $3 \mathrm{~g}, 1000 \mathrm{~mL} \mathrm{H}_{2} \mathrm{O}, \mathrm{pH}$ 6.0). After $48 \mathrm{~h}$ of cultivation at $28{ }^{\circ} \mathrm{C}$ while shaking at $120 \mathrm{rpm}$, the mycelia were harvested and transferred to the same medium containing no peptone, and $1 \% \mathrm{D}$-cellobiose was added. The cultures were then incubated at $28{ }^{\circ} \mathrm{C}$ while shaking at $120 \mathrm{rpm}$ for $0,4,8$, or $12 \mathrm{~h}$. All of the assays were performed in triplicate.

\section{Enzyme assays}

All enzyme activities were presented as specific activities using international units (IU) per $\mathrm{mL}$ supernatant. The FPase (FPA) activity and endoglucanase (EG) activity were measured by the DNS method with glucose as a standard, as described in $[47,48]$. The $\beta$-glucosidase activity was determined using $p$-Nitrophenyl- $\beta$-Dglucopyranoside (pNPG) as a substrate based on the reported method by Takashima [49]. The exo-1,4- $\beta$ glucanase $(\mathrm{CBH})$ activity was measured as reported by Deshpande [50].

\section{Sequencing and assembly}

The sequenced reads were examined for low quality reads by filtering reads with adaptor sequences of $>10 \%$ $\mathrm{Ns}$ or $>50 \%$ nucleotides of quality $(\mathrm{Q}) \leq 5$. The final output was the clean reads. A genome survey was performed with the clean reads by counting the frequency of 17-mers from 3.8 Gb of data from YYH13 and YYH16. The K-mer frequency was plotted using R.
The assembly was performed using SOAPdenovo [51] with K-mer ranging from 21 to 111, and the assembly with the largest N50 was chosen. Scaffolds that are less than 500 bp were removed in the final assembly.

\section{Phylogenetic analysis of YYH13 and YYH16}

Genomic sequence spanning ITS1 and ITS2 were extracted from a previous sequencing study [21]. A total of 54 ITS1-ITS2 sequences were used as queries in BLAST against YYH13 and YYH16 assemblies. A phylogenetic tree with the ITS1-ITS2 sequences from YYH13 and YYH16 was built by first aligning 92 other sequences from JGI database (http://jgi.doe.gov/) and GenBank (https://www.ncbi.nlm.nih.gov/genbank/). Species recognition in Trichoderma is usually based on the application of the genealogical concordance phylogenetic species recognition concept based on the partial genes sequences of translation elongation factor 1a (Tef-1), calmodulin (cal1-1), and chitinase 18-5 (chi18-5) [52]. To further confirmed that YYH13 and YYH16 are strains of the $T$. hamatum species, the concatenated sequence of Tef-1, cal1-1, and chi18-5 genes were used to construct a phylogenetic tree as described. Consensus tree was inferred using the neighbour-joining method. Bootstrap analysis was conducted using the MEGA 5.1 (http://www. megasoftware.net/) with 1000 replications to obtain the confidence value for the aligned sequence dataset. A phylogenetic tree was constructed via maximum parsimony.

\section{Genome annotation}

Gene annotation was performed using GeneMark-ES 2.3.e [53] on YYH13, YYH16, and GD12 assemblies. The GD12 assembly and FgeneSH annotation on GD12 was downloaded from JGI. Each gene was annotated for its putative function using GO, the NCBI-nr database, KOG, and KEGG. Putative functional domains were annotated using Pfam (Protein families). Genes with putative CAZyme functions were annotated using dbCAN [54] with version 4 of the database. A valid annotation required database alignment $>80$ aa, E-value $<1 \mathrm{e}-5$, and percent alignment coverage $>30 \%$. Genes with putative protease functions were annotated using the MEROPS database Release 9.13 (Rawlings et al. [32]) with BlastP PID $>35 \%$, E-value $<1 e-5$, and bit score $>30$. Repetitive element annotation was performed using RepeatModeler and RepeatMasker (www.repeatmasker.org) under the default settings.

\section{Genome sequence analysis}

Orthologous relationships were determined first using Inparanoid [55] under the default settings. Each one-toone orthologous relationship was examined for possible gene model improvement. Gene model improvement 
was performed via reciprocal genBlastG [56] comparisons between YYH13 and YYH16. Thus, genBlastG was performed with YYH13 genes as the query and the YYH16 genome as the target, and vice versa. The genBlast $G$ model must lie within the same coordinates as the original gene model. The revised model is from the highest global PID among the three gene pairs (I: Original YYH13 gene and original YYH16 gene; II: Original YYH13 gene and genBlastG model in YYH16 genome; III: Original YYH16 gene and genBlastG model in YYH13 genome).

The gene model revision in GD12 was performed first using the revised YYH13 gene set as the query and further improved using YYH16. If a gene model was improved by both YYH13 and YYH16, only the revision from YYH13 was kept. Finally, the mean PID and standard deviation were calculated based on the revised oneto-one relationships for each pair of genome.

Genome difference genes were identified using TribeMCL (inflation value =1.6) [57] with the original gene set. Each genome difference genes were examined using genBlastG. For each genome difference gene, genBlastG was used against the two other genomes under the default settings. If the genBlastG model and the query showed a global PID $\geq$ mean PID-2 standard deviations, then the genome difference gene was considered a false positive and filtered.

\section{Synteny analysis}

The synteny blocks between two genomes were analyzed using orthocluster with parameters "-f-rs". The perfect synteny blocks did not allow for any mismatches. Imperfect synteny blocks were obtained with additional "-i 5-o 5" parameters. The orthologous relationships used as input were the one-to-one relationships based on the Inparanoid results. The Circos diagram was constructed by including only the scaffold containing gene models. The genome on the right was considered the reference, and the genome on the left were reordered.

\section{Gene family comparison}

The gene family annotation for CAZyme and proteases were annotated to the orthologous relationships from Inparanoid. Genomes that were missing orthologous genes in the family were examined using genBlast $G$ revision to ensure the difference observed was not due to misassembly or misannotation. First, if genBlastG was able to produce a gene model in the target genome with percent identity (PID) > mean PID-2 standard deviation, then the model was considered a valid homologous gene. Otherwise, it was considered a low PID and was filtered. If gene family expansion had occurred, a valid genBlastG model may overlap with an existing gene annotation.
Thus, if a valid genBlastG model overlapped with an existing gene annotation that already had an ortholog, then the genBlast $G$ model was filtered. The genBlastG models were also annotated using dbCAN and MEROPS, as previously described, and marked as "No annotated function" if the sequence did not pass the annotation criteria.

\section{$\mathrm{Ka} / \mathrm{Ks}$ analysis}

Synonymous and non-synonymous mutations were determined from pair-wise alignments of revised one-toone relationships. $\mathrm{Ka} / \mathrm{Ks}$ ratio was calculated using $\mathrm{Ka} / \mathrm{Ks}$ Calculator 2.0 using the MYN algorithm.

\section{Real-time polymerase chain reaction}

Mycelia were harvested, frozen and ground in liquid nitrogen. Total RNAs from the mycelia were extracted using TRIzol (Invitrogen, USA), and polyA mRNAs were purified using a PolyATract mRNA Isolation System (Promega, Madison, WI) according to the manufacturer's instructions. All cDNAs were synthesized via reverse transcription reaction performed using ReverTra Ace (Toyobo, Japan) at $42{ }^{\circ} \mathrm{C}$ for $1 \mathrm{~h}$ and then $85^{\circ} \mathrm{C}$ for $15 \mathrm{~min}$ to stop the reaction. The standard protocol was $95^{\circ} \mathrm{C}$ for $10 \mathrm{~min}$ followed by 40 cycles at $95^{\circ} \mathrm{C}$ for $10 \mathrm{~s}$ and $59^{\circ} \mathrm{C}$ for $50 \mathrm{~s}$. All reactions were performed in triplicate. The GAPDH was used as internal reference gene. GH1 family beta-glucosidase genes (YYH137902, YYH13952, YYH134611, YYH1311079, YYH1612, YYH1611163, YYH164503) were classified using dbcan analysis system, including $Y Y H 1311079$ was specific gene, YYH137902 and $Y Y H 1612, Y Y H 134611$ and $Y Y H 164503, Y Y H 13952$ and $Y Y H 1611163$ were between homologous genes. qRT-PCR was performed using PikoReal 96-well thermal cyclers (Thermo, USA) with primers and temperatures as described in Additional file 4.

\section{Cloning and construction of recombinant plasmid expression vector}

Escherichia coli strains BL21 (DE3) (Invitrogen, Carlsbad, CA, USA) were used for cloning and expression experiments. E. coli strains were grown in Luria-Bertani (LB) broth or on agar plates at $37^{\circ} \mathrm{C}$. Ampicillin (Sangon Biotech, Shanghai, China) was used in growth media when required. The vectors pGEX-KG (Takara, China) was used for polymerase (Additional file 5) chain reaction (PCR) cloning. The coding sequence of YYH1311079 was amplified by PCR using a sense primer (5'-CGCGG ATCCATGTCCAAAGAGGCGTC GATGTTC-3') and an antisense primer (5'-CCCAAGCTTCTATATCCCT CTGCGC CTGGCAAAAG-3') with BamHI and HindIII restriction enzyme sites (underlined), respectively. The protocol is an initial denaturation at $95{ }^{\circ} \mathrm{C}$ for $1 \mathrm{~min}$ 
followed by 30 cycles of amplification $\left(95{ }^{\circ} \mathrm{C}\right.$ for $10 \mathrm{~s}$, $58{ }^{\circ} \mathrm{C}$ for $50 \mathrm{~s}$, and $72{ }^{\circ} \mathrm{C}$ for $2 \mathrm{~min}$ ) and an additional extension step at $72{ }^{\circ} \mathrm{C}$ for $10 \mathrm{~min}$. Two white single colonies were selected and inoculated to $5 \mathrm{~mL} \mathrm{LB}$ culture solution containing $5 \mu \mathrm{L} 100 \mu \mathrm{g} / \mathrm{mL}$ ampicillin and underwent shake culture at $37^{\circ} \mathrm{C}$ overnight. The plasmid DNA was extracted using alkaline lysis, and underwent two single digestions with BamHI and HindIII respectively, and then electrophoresis with $1 \%$ agarose gel was done to identify the positive clone. Some of the constructed pGEX-KG/YYH1311079 expression plasmid were sent to Shen Zhen HuiDa an corp in China for sequencing.

\section{Additional files}

Additional file 1. Ka/Ks calculations for each orthologs pair between YYH13, YYH16, and GD12.

Additional file 2. Genome difference genes annotated with NCBI NR, GO, KEGG, KOG, and Pfam.

Additional file 3. CAZyme families that; show difference in member numbers between $\mathrm{YYH} 13$ and $\mathrm{YYH} 16$.

Additional file 4. Primers used in qRT-PCR for validation of differentially expressed genes.

Additional file 5. Primers used in PCR for amplified products of YYH1311079 gene.

\section{Abbreviations}

pNPGase: the $\beta$-glucosidase activity; pNPCase: the CBH activity; CMCase: the CMC activity; FPase: the filter paper activity; PDA: potato dextrose agar; IU: international units; pNPG: p-nitrophenyl- $\beta$-D-glucopyranoside; PCS: the pretreated corn stover; GAPDH: glyceraldehyde-3-phosphate dehydrogenase.

\section{Authors' contributions}

$C P, J C$, and NC designed research. CP,BL,YH AND XY performed research. $X X, L C$ and $\mathrm{SS}$ contributed reagents and analytic tools. $\mathrm{CP}, \mathrm{BL}, \mathrm{YS}$ and $\mathrm{YH}$ analyzed data. CP,NC, and YS wrote the paper. All authors read and approved the final manuscript.

\section{Author details}

${ }^{1}$ Hunan Provincial Key Laboratory of Phytohormones and Growth Development, Hunan Provincial Key Laboratory for Crop Germplasm Innovation and Utilization, Hunan Agricultural University, Changsha 410128, China. ${ }^{2}$ College of Life Science and Technology, Huazhong Agricultural University, Wuhan 430070, China. ${ }^{3}$ National Center for Citrus Improvement, Hunan Agricultural University, Changsha 410128, China. ${ }^{4}$ Wuhan Frasergen Bioinformatics Co. Ltd, 666 Gaoxin Road, East Lake High-tech Zone, Wuahn 430075, China. ${ }^{5}$ Department of Molecular Biology and Biochemistry, Simon Fraser University, Burnaby, BC V5A 5S6, Canada.

\section{Acknowledgements}

The present study was supported by National Natural Science Foundation of China (31570372), Scientific research outstanding youth project of Hunan Provincial Education Department (15B112), Science and technology project of Hunan Province (2015NK3005), The Natural Science foundation of Hunan Province (2016JJ3074), Science and technology project of Changsha City (kh1601179), The Open Science Foundation of Hunan Provincial Key Laboratory for Germplasm Innovation and Utilization of Crop (15KFXM13).

\section{Competing interests}

The authors declare that they have no competing interests.

\section{Availability of data and materials}

Data supporting the conclusions of this article are included within the article.

\section{Publisher's Note}

Springer Nature remains neutral with regard to jurisdictional claims in published maps and institutional affiliations.

Received: 1 December 2016 Accepted: 9 April 2017

Published online: 19 April 2017

\section{References}

1. Castro LDS, Pedersoli WR, Antoniêto ACC, Steindorff AS, Silva-Rocha R, Martinez-Rossi NM, Rossi A, Brown NA, Goldman GH, Faça VM, et al. Comparative metabolism of cellulose, sophorose and glucose in Trichoderma reesei using high-throughput genomic and proteomic analyses. Biotechnol Biofuels. 2014;7(1):196-202.

2. Fang T, Liao B, Lee S. Enhanced production of xylanase by Aspergillus carneus M34 in solid-state fermentation with agricultural waste using statistical approach. New Biotechnol. 2009;27(1):25-32.

3. Sanatan PT, Lomate PR, Giri AP, Hivrale VK. Characterization of a chemostable serine alkaline protease from Periplaneta americana. BMC Biochem. 2013;14(22):1-9.

4. He J, Kieselbach T, Jönsson LJ. Enzyme production by filamentous fungi: analysis of the secretome of Trichoderma reesei grown on unconventional carbon source. Microb Cell Fact. 2010;10(47):68.

5. Baba Y, Sumitani Jl, Tani S, Kawaguchi T. Characterization of Aspergillus aculeatus, $\beta$-glucosidase 1 accelerating cellulose hydrolysis with Trichoderma, cellulase system. AMB Express. 2015;5(1):1-9.

6. Bussink HJ, Buxton FP, Fraaye BA, de Graaff LH, Visser J. The polygalacturonases of Aspergillus niger are encoded by a family of diverged genes. Eur J Biochem. 1992;208(1):83-90.

7. Patil SR, Dayanand A. Optimization of process for the production of fungal pectinases from deseeded sunflower head in submerged and solid-state conditions. Bioresour Technol. 2006;97(18):2340-4.

8. Polizeli ML, Rizzatti AC, Monti R, Terenzi HF, Jorge JA, Amorim DS. Xylanases from fungi: properties and industrial applications. Appl Microbiol Biotechnol. 2005:67(5):577-91.

9. Mandels M, Reese ET. Induction of cellulase in Trichoderma viride as influenced by carbon sources and metals. J Bacteriol. 1957;73:269-78.

10. Mukherjee PK, Horwitz BA, Herreraestrella A, Schmoll M, Kenerley CM. Trichoderma research in the genome era. Annu Rev Phytopathol. 2013;51(1):105-29.

11. Druzhinina IS, Shelest E, Kubicek CP. Novel traits of Trichoderma, predicted through the analysis of its secretome. FEMS Microbiol Lett. 2012;337(1):1-9.

12. Seid V, Seiboth B. Trichoderma reesei: genetic approaches to improving strain efficiency. Biofuels. 2010;1 (2):343-54.

13. Beitel SM, Knob A. Penicillium miczynskii $\beta$-glucosidase: a glucose-tolerant enzyme produced using pineapple peel as substrate. Ind Biotechnol. 2013;9:103-8.

14. Karkehabadi S, Helmich KE, Kaper T, Hansson H, Mikkelsen NE, Gudmundsson M, Piens K, Fujdala M, Banerjee G, Scott-Craig JS, et al. Biochemical characterization and crystal structures of a fungal family 3 beta-glucosidase, Cel3A from Hypocrea jecorina. J Biol Chem. 2014:289(45):31624-37.

15. Duff SJB, Cooper DG, Fuller OM. Cellulase and beta-glucosidase production by mixed culture of Trichoderma reesei Rut C30 and Aspergillus phoenicis. Biotechnol Lett. 1985;7:185-90.

16. Chuang YC, Li WC, Chen CL, Hsu WC, Tung SY, Kuo HC. Trichoderma reesei meiosis generates segmentally aneuploid progeny with higher xylanaseproducing capability. Biotechnol Biofuels. 2015;8(1):1-15.

17. Cheng P, Song W, Gong X, Liu YS, Xie WG, Huang LH, Hong YH. Proteomic approaches of Trichoderma hamatum to control Ralstonia solanacearum causing bacterial wilt. Int J Agric Biol. 2015;17(6):987-90.

18. Kattner D. The pathogenicity of Trichoderma hamatum on Norway spruce (Picea abies) seedlings. Allgemeine Forst Und Jagdzeitung. 1990;161:1-6. 
19. El-Hassan SA, Gowen SR, Pembroke B. Use of Trichoderma hamatum for biocontrol of lentil vascular wilt disease: efficacy, mechanisms of interaction and future prospects. J Plant Prot Res. 2013;53(1):12-26.

20. Toyama H. $1 \mathrm{Hp} 20$ Enhancement of the degrading ability of microcrystalline cellulose in the selected strain derived from Trichoderma reesei QM9414 treated with colchicine under lower temperature conditions. Manag Decis. 2013;52(5):934-49.

21. Studholme DJ, Winsbury R, Perera V, Ryder L. Investigating the beneficial traits of Trichoderma hamatum GD12 for sustainable agriculture-insights from genomics. Front Plant Sci. 2013;4:258.

22. Kubicek CP, Martinez DA, Druzhinina IS, Thon M. Comparative genome sequence analysis underscores mycoparasitism as the ancestral life style of Trichoderma. Genome Biol. 2011;12(4):81-9.

23. Baroncelli R, Piaggeschi G, Fiorini L, Bertolini E, Zapparata A, Pè ME, Sarrocco S, Vannacci G. Draft whole-genome sequence of the biocontrol agent Trichoderma harzianum T6776. Genome Announc. 2015;3(3):1-2.

24. Martinez D, Berka RM, Henrissat B, Saloheimo M, Arvas M, Baker SE, Chapman J, Chertkov O, Coutinho PM, Cullen D, et al. Genome sequencing and analysis of the biomass-degrading fungus Trichoderma reesei (syn. Hypocrea jecorina). Nat Biotechnol. 2008;26(5):553-60.

25. Sun RY, Liu ZC, Fu K, Fan L, Jie C. Trichoderma biodiversity in China. J Appl Genet. 2012;53(3):343-54.

26. Parra G, Bradnam K, Korf I. CEGMA: a pipeline to accurately annotate core genes in eukaryotic genomes. Bioinformatics. 2007;23(9):1061-7.

27. Levasseur A, Saloheimo M, Navarro D, Andberg M, Pontarotti P, Kruus $K$, Record E. Exploring laccase-like multicopper oxidase genes from the ascomycete Trichoderma reesei: a functional, phylogenetic and evolutionary study. BMC Biochem. 2010;11(1):1-10.

28. Berlin A, Maximenko V, Bura R, Kyu-Young K, Neil G, Jack S. A rapid microassay to evaluate enzymatic hydrolysis of lignocellulosic substrates. Biotechnol Bioeng. 2006;93(5):880-6.

29. Machida M, Asai K, Sano M, Toshihiro T, Toshitaka K, Goro T, Kusumoto KI, Arima T, Akita O, Kashiwagi Y, et al. Genome sequencing and analysis of Aspergillus oryzae. Nature. 2005;438(7071):1157-61.

30. Ambro VH. Conserved functions of yeast genes support the duplication, degeneration and complementation model for gene duplication. Genetics. 2005;171(4):1455-61.

31. Lange C, Weld RJ, Cox MP, Bradshaw RE, Mclean KL, Stewart A, Steyaert JM. Genome-scale investigation of phenotypically distinct but nearly clonal Trichoderma strains. PeerJ. 2016;4(5):e2023.

32. Rawlings ND, Waller M, Barrett AJ, Bateman A. MEROPS: the database of proteolytic enzymes, their substrates and inhibitors. Nucleic Acids Res. 2014;42(Database Issue):503-9.

33. Do VL, Gómez-Mendoza DP, Kim MS, Kim MS, Pandey A, Ricart CA, Ximenes FFE, Sousa MV. Secretome analysis of the fungus Trichoderma harzianum grown on cellulose. Proteomics. 2012;12(17):2716-28.

34. Kanauchi M, Bamforth CW. Growth of Trichoderma viride on crude cell wall preparations from barley. J Agric Food Chem. 2001;49(2):883-7.

35. Elad $Y$, Kapat A. The role of Trichoderma harzianum protease in the biocontrol of Botrytis cinerea. Eur J Plant Pathol. 1999;105(105):177-89.

36. Rawlings ND, Barrett AJ. Evolutionary families of peptidases. Biochem J. 1993;290:205-18.

37. Rawlings ND, Barrett AJ, Bateman A. MEROPS: the database of proteolytic enzymes, their substrates and inhibitors. Nucleic Acids Res. 2012:40:343-50.

38. Vincent L, Hemalatha GR, Elodie D, Coutinho PM, Bernard H. The carbohydrate-active enzymes database (CAZy) in 2013. Nucleic Acids Res. 2014:42:490-5.

39. Druzhinina IS, Verena SS, Alfredo HE, Horwitz BA, Kenerley CM, Enrique M Trichoderma: the genomics of opportunistic success. Nat Rev Microbiol. 2011;9(10):749-59.
40. James R, Ketudat C, Asim E. $\beta$-Glucosidases. Cell Mol Life Sci. 2010;67(67):3389-405.

41. Thornton CR. An immunological approach to quantifying the saprotrophic growth dynamics of Trichoderma species during antagonistic interactions with Rhizoctonia solani in a soil-less mix. Environ Microbiol. 2004;6(4):323-34.

42. Bischof R, Fourtis L, Limbeck A, Gamauf C, Seiboth B, Kubicek CP. Comparative analysis of the Trichoderma reesei transcriptome during growth on the cellulase inducing substrates wheat straw and lactose. Biotechnol Biofuels. 2013;6(1):1-14

43. Hantsch L, Braun U, Haase J, Purschke O, Scherer-Lorenzen M, Bruelheide $H$. No plant functional diversity effects on foliar fungal pathogens in experimental tree communities. Fungal Divers. 2014;66(1):1-13.

44. And KC, Kover PX. The red queen hypothesis and plant/pathogen interactions. Annu Rev Phytopathol. 1996;34(34):29-50.

45. George SP, Ahmad A, Rao MB. Studies on carboxymethyl cellulase produced by an alkalothermophilic actinomycete. Bioresour Technol. 2001;77(2):171-5.

46. Shin HJ, Yang JW. Galactooligosaccharide synthesis from lactose by Penicillium funiculosum cellulase. Biotechnol Lett. 1996;18(2):143-4.

47. Xiao Z, Storms R, Tsang A. Microplate-based filter paper assay to measure total cellulase activity. Biotechnol Bioeng. 2004;88(7):832-7.

48. Xiao Z, Storms R, Tsang A. Microplate-based carboxymethylcellulose assay for endoglucanase activity. Anal Biochem. 2005;342(1):176-8.

49. Takashima S, Nakamura A, Hidaka M, Masaki H, Uozumi T. Molecular cloning and expression of the novel fungal beta-glucosidase genes from Humicola grisea and Trichoderma reesei. J Biochem. 1999;125(4):728-36.

50. Deshpande MV, Eriksson KE, Göran Pettersson L. An assay for selective determination of exo-1,4,- $\beta$-glucanases in a mixture of cellulolytic enzymes. Anal Biochem. 1984;138(2):481-7.

51. Li Y, Hu Y, Bolund L, Wang J. State of the art de novo assembly of human genomes from massively parallel sequencing data. Hum Genom. 2010;4(4):271-7.

52. Druzhinina IS, Komoń-Zelazowska M, Ismaiel A, Jaklitsch W, Mullaw T, Samuels GJ, Kubicek CP. Molecular phylogeny and species delimitation in the section Longibrachiatum of Trichoderma. Fungal Genet Biol. 2012:49(5):358.

53. Besemer J, Lomsadze A, Borodovsky M. GeneMarkS: a self-training method for prediction of gene starts in microbial genomes. Implications for finding sequence motifs in regulatory regions. Am Bank. 2001;29(12):2607-18.

54. Yanbin $Y$, Xizeng $M$, Jincai $Y$, Xin C, Fenglou M, Ying X. dbCAN: a web resource for automated carbohydrate-active enzyme annotation. Nucleic Acids Res. 2012:40:445.

55. Ostlund G, Schmitt T, Forslund K, Köstler T, Messina DN, Roopra S, Frings O, Sonnhammer EL. InParanoid 7: new algorithms and tools for eukaryotic orthology analysis. Nucleic Acids Res. 2010;38:196-203.

56. She R, Chu JS, Uyar B, Wang J, Wang K, Chen N. genBlastG: using BLAST searches to build homologous gene models. Bioinformatics. 2011;27(15):2141-3.

57. Enright AJ, Van Dongen S, Ouzounis CA. An efficient algorithm for largescale detection of protein families. Nucleic Acids Res. 2002;30(7):1575-84.

\section{Submit your next manuscript to BioMed Central and we will help you at every step:}

- We accept pre-submission inquiries

- Our selector tool helps you to find the most relevant journal

- We provide round the clock customer support

- Convenient online submission

- Thorough peer review

- Inclusion in PubMed and all major indexing services

- Maximum visibility for your research

Submit your manuscript at www.biomedcentral.com/submit 